\title{
As políticas educacionais e a área de Ciências da Religião e Teologia no Brasil
}

\author{
Educational policies and the area of Sciences of Religion and Theology in Brazil
}

\author{
Jonatas Câmara* \\ Ana Lúcia Ferreira Câmara** \\ Maria José Costa Lima*** \\ Thiago Jonatas Ferreira Câmara ${ }^{* * * *}$
}

\begin{abstract}
Resumo
As políticas educacionais no Brasil estão em permanente discussão. Tanto na academia quanto nas redes de comunicação das tecnologias da informação, a educação não se mostra estática, mas dinâmica, sendo questionada e instigada a contemplar cada vez mais a diversidade brasileira, seja em questões culturais, ideológicas ou de crenças. $\mathrm{O}$ artigo, a partir de pesquisa bibliográfica e contemplando documentos normativos, busca compreender a politica educacional brasileira em seus pressupostos básicos para adentrar especificamente na área das Ciências da Religião e Teologia e verificar como ela está em desenvolvimento enquanto área de saber. A área da Teologia contribui para compreender o multiculturalismo brasileiro, auxiliando em questões éticas e no desenvolvimento da autonomia intelectual e do pensamento crítico.
\end{abstract}

Palavras-chave

Educação. Políticas Educacionais. Ciências da Religião e Teologia.

\begin{abstract}
The educational policies in Brazil are in permanent discussion. In academic circles as well as in the communication networks of information technology, education is not static, but dynamic, being questioned and increasingly instigated to contemplate the Brazilian diversity, be it on cultural, ideologic or belief issues. The article, based on bibliographic research and contemplating normative documents, seeks to comprehend the Brazilian educational policy in its basic pressupositions to then specifically penetrate the area of Sciences of Religion and Theology and verify how it is developing as an area of knowledge. The area of Theology contributes to understand the Brazilian multiculturalism, helping in ethical
\end{abstract}

[Texto recebido em agosto de 2017 e aceito em janeiro de 2018, com base na avaliação cega por pares realizada por pareceristas ad hoc]

* Doutorando DINTER Faculdades EST/Faculdades Boas Novas, Amazonas.

** Doutoranda DINTER Faculdades EST/Faculdades Boas Novas, Amazonas.

*** Doutoranda DINTER Faculdades EST/Faculdades Boas Novas, Amazonas.

${ }^{* * * *}$ Doutoranda DINTER Faculdades EST/Faculdades Boas Novas, Amazonas. 
issues and in the development of the intellectual autonomy and of critical thought.

\section{Keywords}

Education. Educational Policies. Sciences of Religion and Theology.

\section{Introdução}

O presente artigo tem por objetivo refletir acerca da área das Ciências da Religião e Teologia sob a perspectiva das políticas educacionais. Trata-se de uma reflexão sobre o que vem a ser a política nacional brasileira e como as Ciências da Religião e Teologia são inseridas nesse debate. A discussão se dá para além dos muros da educação, uma vez que trata de uma temática inerente ao ser humano, na sua individualidade.

Está dividido em quatro partes. Inicialmente define o que vem a ser política educacional, com vistas a uma política educacional em se pensando num projeto de Nação e não como projeto de governo da ideologia que está no poder.

Em seguida, destaca, brevemente, a política pública educacional brasileira através da Constituição Federal e da Lei de Diretrizes e Bases da Educação Nacional (LDBEN). Ou seja, expõe-se a legislação que define os rumos para uma política educacional nacional.

Desta forma, a política educacional à luz do multiculturalismo é refletida em seguida. Seja para a área da Teologia, seja para considerar a diversidade cultural em geral no Brasil, o elogio à diferença se mostra como pressuposto básico.

Por fim, aborda as Ciências da Religião e Teologia na contemporaneidade, tendo como base o Documento de Área - Teologia, da CAPES. Percebe-se o quanto se avançou na reflexão acerca da área da Teologia, inserindo uma área de conhecimento importante para a formação integral, contemplando a diversidade e a cientificidade.

\section{Política educacional brasileira: conceituações}

Ao se falar sobre políticas educacionais, há que se destacar o que vem a ser política educacional. Por política, Ney recorre aos termos em inglês policy - programa de ação - e politics - correspondente ao espaço da política partidária. No caso do objeto de estudo, o termo política se refere ao "programa de ação", "[...] no sentido dos fins a serem alcançados por uma administração ou gestão". ${ }^{1}$ Nesse sentido, é importante pensar a educação num projeto de construção de um Estado-Nação, entendendo por isso um "grupo complexo, constituído por grupos sociais distintos que, ocupando uma mesma base física, compartilham da mesma evolução histórico-cultural e dos mesmos valores" ${ }^{2}$

1 NEY, Antonio. Política Educacional: organização e estrutura da educação brasileira. Rio de Janeiro: WAK, 2008. p. 17.

2 ESCOLA SUPERIOR DE GUERRA apud NEY, 2008, p. 19. 
Etimologicamente, a palavra "política" 3 tem sua origem grega, politikós, que tem a ver com assuntos políticos, ciência política: ramo das ciências sociais que trata do governo e da organização do Estado. Significa a condição de cidadão, de se expressar de forma livre acerca dos assuntos que o envolvem, ou seja, pertinentes à organização da vida no local em que habita. De acordo com Shiroma,

[...] o termo "política" prenuncia uma multiplicidade de significados, presentes nas múltiplas fases históricas do Ocidente. Em sua acepção clássica, deriva de um adjetivo originado de polis - politikós - e refere-se à cidade e, por conseguinte, ao urbano, ao civil, ao público, ao social. [...] O conceito de política encadeou-se, assim, ao do poder do Estado - ou sociedade política - em atuar, proibir, ordenar, planejar, legislar, intervir, com efeitos vinculadores a um grupo social definido e ao exercício do domínio exclusivo sobre um território e da defesa de suas fronteiras. ${ }^{4}$

Já a palavra "pública" 5 tem sua origem no latim, publicus, significa relacionada ao povo; ou que se refere ao povo em geral; interesse público. Assim, Política Pública pode ser compreendida como a busca do povo por benefícios que são seus de direito.

As Políticas Públicas são responsabilidade do Estado, sendo que aos governos cabe a responsabilidade pela garantia dos direitos e deveres dos cidadãos. E, nestes direitos, reúnem-se a educação, a saúde, a moradia, a previdência, entre outras políticas consideradas sociais e de extrema importância para o povo. Shiroma conclui que o termo "políticas"

[...] refere-se ao conjunto de atos, de medidas e direcionamentos abrangentes e internacionais, estabelecidos no campo econômico e estendidos à educação pública pelo Banco Mundial, dirigidas aos Estados da América Latina e assumidos pelos governos locais, que tratam de disciplinar, de ordenar e de imprimir a direção que se deseja para a educação nacional. ${ }^{6}$

As Políticas Públicas representam fatores determinantes e de fundamental importância para a educação. Höfling defende a "[...] educação como uma política pública social, uma política pública de corte social, de responsabilidade do Estado [...]". ${ }^{7}$ As Políticas Públicas estão envolvidas com o social, englobam a sociedade, favorecendo a educação, o que é preponderante para seu desenvolvimento.

\footnotetext{
ABBAGNANO, Nicola. Dicionário de filosofia. São Paulo: Martins Fontes, 2007.

SHIROMA, Eneida Oto. Política Educacional. 4. ed. Rio de Janeiro: Lamparina, 2007. p. 7.

ABBAGNANO, 2007.

SHIROMA, 2007, p. 7.

HÖFLING, Eloísa de Mattos. Estado e Políticas (Públicas) Sociais. Cadernos Cedes, ano XXI, n. 55, nov. 2001. p. 30-41. Disponível em: <http://www.scielo.br/pdf/ccedes/v21n55/5539.pdf>. Acesso em: 5 jun. 2017. p. 31
}

Protestantismo em Revista | São Leopoldo | v. 43, n. 2 | p. 103-119 | jul./dez. 2017

Disponível em: <http://periodicos.est.edu.br/index.php/nepp> 
Assim, as Políticas Públicas são responsáveis por viabilizar recursos à Educação, entre eles os financeiros, logísticos, etc., fundamentais ao seu desenvolvimento. Ainda que forneça recursos para a educação escolar de modo especial desde a década de 1990, os governos têm desenvolvido parcerias com organizações da sociedade civil por meio das quais se realizam projetos socioeducativos no âmbito da Educação Social.

Deste modo, as Políticas Públicas pretendem articular a política do sistema de educação e as demais políticas, que promovem os direitos humanos dos cidadãos, especialmente das classes populares.

Morin ${ }^{8}$ defende ideias sobre a educação que podem parecer utópicas. Dificuldade em colocar em prática não somente para o Brasil, mas para o mundo, uma vez que a tendência das políticas educacionais é priorizar cada vez mais a educação técnica, específica, em detrimento da formação de um ser humano mais amplo, ou completo, capaz de enfrentar os desafios dos tempos atuais. Ele propõe a formação de cidadãos polivalentes, o contrário do que verificamos na prática, ou seja, uma robotização do ser humano, assim como Charles Chaplin já preconizava em seu filme Tempos Modernos.

Morin ainda nos fornece ferramentas concretas de como trabalhar na educação, a partir da nossa realidade, a condição humana. Trata-se da transdisciplinaridade. Neste aspecto, ao pensar em gestão de processos educativos, a transdisciplinaridade é, sem dúvida, crucial para a formação do cidadão como um todo. No entanto, as políticas educacionais deixam de lado as questões que para Morin são determinantes para uma Educação exitosa em todos os sentidos. Assim, pedagogos, juntamente com o corpo docente, podem transformar a educação, fazendo do utópico o possível.

A educação é uma das necessidades do povo. O Estado é o responsável pelo povo, logo, deve procurar pelo seu bem-estar. Ney alerta, no entanto, que:

[...] o atendimento dessas necessidades se torna complicado em virtude dos recursos disponíveis, pois não existe o suficiente para satisfazer todas as necessidades. Como os recursos são limitados, o Estado irá priorizar quais as necessidades que devem ser atendidas, definindo políticas públicas para atender a elas. ${ }^{9}$

A definição das políticas públicas se dá de acordo, portanto, com as necessidades do povo e em conformidade com a "Vontade Nacional" para manter os objetivos nacionais e fundamentais: "[...] as ações a serem empreendidas para satisfazer uma necessidade deverão estar de acordo com os anseios da sociedade nacional".$^{10}$

8 MORIN, Edgar. Os sete saberes necessários à educação do futuro. 12. ed. São Paulo: Cortez; Brasília: UNESCO, 2007.

9 NEY, 2008, p. 19.

10 NEY, 2008, p. 20. 
Há que se ressaltar, no entanto, que há também os objetivos governamentais nos objetivos de um Estado. Estes são voltados ao atendimento de situações conjunturais de um ou mais governos. ${ }^{11}$ Nesse caso, a educação, tema deste artigo, pode vir a ser também um objetivo de governo, mas não pode se tornar uma forma de legitimar uma ideologia educacional com base nas convicções partidárias deste governo. A educação não pode ser uma política educacional partidária, mas uma política educacional com objetivo de atender a Nação, contribuindo para a construção deste Estado-Nação que incentiva a prática da cidadania.

Essa construção pode (e deve) ser feita em conjunto com a sociedade civil, “[...] o segundo braço do Estado, onde estão os órgãos e as instituições (clubes, associações, sindicatos, escolas, etc.) que vão construir a hegemonia do Estado [...]". ${ }^{12}$

\section{A política pública educacional brasileira}

A educação brasileira possui um ordenamento jurídico-político necessário com o objetivo de construir uma norma, por um lado, e colocá-la em prática, por outro. Nesse sentido, a educação brasileira está apoiada na Constituição Federal de 1988, nos Art. 205 a 214, e pela Lei de Diretrizes e Bases da Educação Nacional (LDBEN n. 9.394/96). Trata-se, segundo Ney,13 da evolução da educação no Brasil., a materialização de diversas conquistas no campo político e ideológico. A partir dessas leis, foram delineados parâmetros e diretrizes curriculares, entre outros planos de ação.

O que se verifica, a partir de Santos, é a necessidade da mediação política:

[...] caracterizada por seu teor pragmático - e também praxiológico, eu diria -, cujos resultados se ligam à ação social concreta e cujo móvel é o poder [...]. Nesse sentido, a dimensão praxiológica do Ordenamento JurídicoPolítico da Educação Brasileira define-se principalmente por seu caráter mutável, cuja mutabilidade refere-se ao dinamismo das forças sociais e políticas presentes no Brasil. ${ }^{14}$

O dinamismo das forças sociais se mostra importante ao se refletir acerca da educação uma vez que evidencia a preocupação em inserir na escola questões do cotidiano da sociedade. Esse aspecto vem contemplar a formação integral do ser humano, não

11 NEY, 2008, p. 23.

12 NEY, 2008, p. 25.

13 NEY, 2008, p. 74.

14 SANTOS, Pablo Silva Machado Bispo dos. Guia Prático da Política Educacional no Brasil: ações, planos, programas e impactos. 2. ed. rev. ampl. São Paulo: Cengage Learning, 2014. p. 17. 
fazendo da escola apenas lugar de depósito de conhecimentos, mas de reflexões que levam à formação cidadã, contemplando o multiculturalismo brasileiro. ${ }^{15}$

Os Parâmetros Curriculares Nacionais (PCN) (para o Ensino Fundamental) e as Diretrizes Curriculares Nacionais (DCN) (para o Ensino Médio) surgem como políticas regulatórias da dimensão pedagógica, no sentido de fornecer subsídios para a elaboração do currículo. Possuem, por sua vez, a linha ideológica daqueles que os construíram. No entanto, não considera a diversidade brasileira ao estabelecer um padrão de educação nacional. Na visão de Santos,

[...] um currículo nacional, ao ser proposto como algo que visa uma identidade nacional, tende a privilegiar os discursos dominantes em detrimento das classes menos favorecidas financeiramente, negando, portanto, a existência de uma identidade. O Brasil, porém, é caracterizado mundialmente por sua mistura de raças, credos e culturas; é isso o que nos torna diferentes. 16

Já no Amazonas a questão é mais complexa do que no restante do Brasil, afirmam Lima e Faria.

A partir de uma mudança na política nacional pela "Década da Educação" e de outros dispositivos legais derivados da Lei de Diretrizes e Bases da Educação de 1996, foi preciso organizar uma grande ação educativa para viabilizar a expansão do ensino médio Amazonas. O desafio era formar milhares de professores numa graduação plena, num Curso Normal Superior. ${ }^{17}$

Há também a problemática da formação docente que, na perspectiva proposta dos PCN's para um ensino interdisciplinar, não possuem um treinamento adequado tornando a prática inoperante. Há o agravante em relação ao ensino religioso e à formação docente necessária para este fim.

15 A partir de Brandenburg, aprende-se que a escola é uma organização sócio-política capaz de efetivar mudanças. "A escola brotou da necessidade da sociedade transmitir o saber historicamente construído e socializado, o saber erudito [e] sua função precípua está no saber elaborado, na Ciência". BRANDENBURG, Laude Erandi. A interação pedagógica no Ensino Religioso. São Leopoldo: Sinodal, 2004. p. 13. A função da escola deve ser também preparar para a vida, diferente daquilo que Brandenburg lembra que, para alguns, a escola tem andado em dissintonia com aquilo de que carece a sociedade, sendo censurada por "não preparar para a vida e não estar ligada às condições da cultura local". BRANDENBURG, 2004, p. 14.

16 SANTOS, 2014, p. 60.

17 LIMA, Paulo Henrique; FARIA, Adriano A.. Proformar: tecnologia e informação para transformar a Amazônia. Disponível em: <https://www.academia.edu/5090929/PROFORMAR_Tecnologia_e_educação_para_transformar_a_A mazônia>. Acesso em: 10 jun. 2017. p. 1. 


\section{Política educacional à luz do multiculturalismo}

A Constituição Federal reconhece a educação como um setor do Estado brasileiro. O Estado é o provedor da educação pública e responsável por ela. Logo, a discussão sobre as Ciências da Religião e a Teologia são também atribuições para o Estado. Essa discussão pode ser vista por dois ângulos:

a) A partir da própria legislação da Carta Magna, em seu Art. 206, Incisos II e III, ao colocar como princípios do ensino a liberdade de aprender, ensinar, pesquisar e divulgar o pensamento, a arte e o saber; e o pluralismo de ideias e concepções pedagógicas. ${ }^{18} \mathrm{E}$ do Art. 210, sobre os conteúdos mínimos para o Ensino Fundamental e do Ensino Religioso de matrícula facultativa. ${ }^{19}$

b) A partir do dinamismo das forças sociais que pedem por um Ensino Religioso a fim de contemplar o multiculturalismo. ${ }^{20}$

Em relação ao item a), pode-se incluir a LDBEN na discussão, pois é a maior política pública regulatória da educação brasileira, uma vez que "[...] sua estrutura define as relações, os acordos e os conflitos que podem se desenrolar no âmbito da educação brasileira" ${ }^{21}$ No seu Art. $3^{\circ}$, contempla os Incisos do Art. 206 da Constituição, acima mencionados e, com o foco no Ensino Religioso, pode-se elencar ainda os Incisos IV e XII, sobre o respeito à liberdade e apreço à tolerância e a consideração com a diversidade étnico-racial. ${ }^{22}$ Esse artigo pode ser visto como uma preparação para o Art. 33, onde o Ensino Religioso é o foco:

O Ensino Religioso, de matrícula facultativa, é parte integrante da formação básica do cidadão e constitui disciplina dos horários normais das escolas públicas de Ensino Fundamental, assegurado o respeito à diversidade cultural religiosa do Brasil, vedadas quaisquer formas de proselitismo. (Redação dada pela Lei n. 9.475, de 22 de julho de 1997).

$\S 1^{\circ}$ Os sistemas de ensino regulamentarão os procedimentos para a definição dos conteúdos do Ensino Religioso e estabelecerão as normas para a habilitação e admissão dos professores. (Incluído pela Lei n. 9.475, de 22 de julho de 1997).

18 Para Santos, os Incisos II e III asseguram a coexistência de ideias plurais e ratificam "[...] o teor liberal da Constituição ao referir-se à liberdade de cátedra e permitir livre expressão de ideias, conceitos e conhecimentos". SANTOS, 2014, p. 23.

19 CONSTITUIÇÃO DA REPÚBLICA FEDERATIVA DO BRASIL. 1988. Disponível em: <http://www.planalto.gov.br/ccivil_03/constituicao/constituicao.htm>. Acesso em: 15 jun. 2017.

20 Há que se considerar nesse dinamismo também os movimentos de oposição ao Ensino Religioso na escola, seja pelo argumento, ainda que inconsistente, de que na escola não se deve falar em religião, ou pelo simples fato de não querer estudar sobre religiões.

21 SANTOS, 2014, p. 30.

22 BRASIL. Lei n. 9.394, de 20 de dezembro de 1996. Estabelece as diretrizes e bases da educação nacional. Disponível em: <http://www.planalto.gov.br/ccivil_03/leis/L9394.htm>. Acesso em: 15 jun. 2017. 
$\S 2^{\circ}$ Os sistemas de ensino ouvirão entidade civil, constituída pelas diferentes denominações religiosas, para a definição dos conteúdos do Ensino Religioso. (Incluído pela Lei n. 9.475, de 22 de julho de 1997). ${ }^{23}$

No entanto, Santos menciona que há disputa entre os credos e a pregação de que o Estado deve ser laico. ${ }^{24} \mathrm{~A}$ disputa entre os credos até é compreensível, cada qual querendo inserir a sua cosmovisão. Trata-se de um diálogo complexo. No entanto, ainda que o Artigo destaque o respeito à diversidade cultural religiosa brasileira, o não proselitismo, que os sistemas de ensino como regulamentadores dos procedimentos e dos conteúdos (ouvindo a sociedade civil e as diferentes denominações religiosas), há a confusão ao se inserir na discussão a questão do Estado laico. ${ }^{25}$ Em nenhum momento há a menção de que se deva seguir determinado credo ou que o Estado seguirá algum. Ocorre justamente o contrário: ao enfatizar que os sistemas de ensino devem consultar a sociedade civil, nas diferentes denominações religiosas, está a legislação cumprindo o princípio do Estado laico brasileiro.

É bem verdade, no entanto, que reunir as denominações religiosas para uma consulta e um estudo em conjunto é uma tarefa de grande complexidade. Santos alerta para a dificuldade, por exemplo, de definir o que realmente é religião e se as seitas também têm lugar nesse diálogo. ${ }^{26}$

Por outro lado, a participação popular passiva em relação à educação em geral, conforme aponta Santos, ${ }^{27}$ não é verificada quando se tratam questões mais polêmicas, que dizem respeito a convicções e crenças, como o Ensino Religioso e a escola sem partido. ${ }^{28} \mathrm{O}$ diálogo e o consenso se tornam difíceis porque mexem com aspectos da vaidade humana, que não se deixa convencer ou olhar com outros olhos determinado tema. No caso do Ensino Religioso, novamente, enfatiza-se a necessidade da visão multicultural. Valcárcel afirma que

3 BRASIL, 1996.

4 SANTOS, 2014, p. 42.

25 Estado laico significa não estar influenciado por qualquer esfera fora do que concerne às atribuições estatais. Reis, a partir do enfoque conceitual jurídico, define como o Estado laico como “[...] aquele indiferente à religiosidade da sociedade, ou seja, o distanciamento do ordenamento jurídico dos dogmas religiosos. Tal distanciamento implica em dois pontos: o Estado não interfere em assuntos religiosos e a religião não interfere nas leis". REIS, Daiane do Carmo. Liberdade Religiosa o Estado Laico: A Relação entre Religião, Estado, Política e Cultura na Contemporaneidade. Disponível em: <http://investidura.com.br/biblioteca-juridica/artigos/direito-constitucional/251509-liberdadereligiosa-o-estado-laico-a-relacao-entre-religiao-estado-politica-e-cultura-na-contemporaneidade>. Acesso em: 04 jun. 2016.

26 SANTOS, 2014, p. 43.

27 SANTOS, 2014, p. 56-57.

28 No caso específico da escola sem partido há uma confusão entre escola partidarizada e escola que politiza, no sentido de discutir ideologias políticas para aprimorar o pensamento crítico, conforme o Art. 35 da LDBEN, no Inciso III, que coloca como uma das finalidades: “[...] o aprimoramento do educando como pessoa humana, incluindo a formação ética e o desenvolvimento da autonomia intelectual e do pensamento crítico; [...]". BRASIL, 1996. 
[...] o multiculturalismo contemporâneo não deve ser confundido com relativismo cultural que nos tem acompanhado há décadas. O relativismo pertence ao paradigma da tolerância, ao passo que o multiculturalismo provém do elogio à diferença, sob a égide do "viva ao próximo!" ${ }^{29}$

Interessante observar que a tolerância mencionada por Valcárcel não faz o elogio da diferença. Tem em seu significado a "paciência". ${ }^{30}$ Nesse sentido, não cabe na discussão falar em tolerância, em ter paciência para com o outro, mas de enxergar a diferença e não questioná-la. Não se está em busca da verdade, mas de expor as diferentes concepções de verdade. A partir de Herbert Marcuse, Abbagnano menciona que a tolerância é inoperante quando está em jogo a paz, a liberdade e a felicidade da existência, "[...] porque equivaleria à repressão de todos os fatores de inovação da realidade social". ${ }^{31}$

No caso da escola sem partido, há que se reportar a Paulo Freire ${ }^{32}$ que, ao refletir acerca da autonomia, afirma seu desejo em discutir uma educação crítica. Ensinar não é transferir conhecimento, mas criar as possibilidades para a sua própria produção e construção. O ser humano é inacabado e, por isso, pode e deve ir além. Com Freire, ${ }^{33} \mathrm{o}$ ensino é a favor das liberdades e contra as autoridades. O ensino leva à tomada consciente de decisões no sentido de mudar aquilo que não está certo. Por isso, a educação é ideológica. O ensino e as ações de Jesus também foram, nesse sentido, ideológicas, na Palavra de Deus. Por isso, a obra de Freire é importante, porque pretende tirar o ser humano do estado de desânimo e de conformismo.

Importante destacar que no caso da Educação Básica, a LDBEN flexibiliza ao dividir em Educação Infantil, Ensino Fundamental e Ensino Médio, fruto da elaboração do Projeto Político Pedagógico (PPP), que dá mais autonomia à escola e há possibilidade da gestão participativa. ${ }^{34}$ Esse aspecto possibilita o envolvimento da comunidade, já que, com a Base Comum Nacional é possível a elaboração de uma base diversificada, pelo sistema estadual ou mesmo pelo estabelecimento escolar. Com isso, o diálogo acerca do Ensino Religioso e do multiculturalismo se torna possível entre os maiores interessados na educação, com possibilidade de decisão própria, não somente na dependência das decisões políticas em nível nacional.

No caso do Ensino Superior, com o objetivo de oferecer formação profissional, educação de qualidade e avançada e funcionar como uma instituição social ao levar à comunidade serviços especializados e comunitários, cujas finalidades são resumidas por

\footnotetext{
VALCÁRCEL, Améli. Ética, um valor fundamental. In: MIRANDA, Danilo Santos de (Org.). Ética e cultura. São Paulo: Perspectiva/SESC, 2004. p. 18-19.

ABBAGNANO, 2007, p. 961.

ABBAGNANO, 2007, p. 962.

32 FREIRE, Paulo. Pedagogia da Autonomia. 25. ed. São Paulo: Paz e Terra, 2002.

FREIRE, 2002.

34 NEY, 2008, p. 82.
} 
Ney como: pesquisa, ensino e extensão. ${ }^{35}$ A partir dessa tríade, há que se atentar para as transformações ocorridas na estrutura universitária que, conforme Barbalho e Castro, ${ }^{36}$ sofreu influência dos processos sociais, levando a uma reestruturação estratégica. Em outras palavras, o Ensino Superior precisa dessa reestruturação devido às novas demandas das sociedades atuais. Nessas demandas, está a formação integral do ser humano, o que contempla o aspecto espiritual. Por isso, as Ciências da Religião e a Teologia mostram-se fundamentais nessa reestruturação. Há uma necessidade de se tratar questões humanas e inerentes ao ser humano, além da mera preparação profissional técnica.

As Ciências da Religião e a Teologia também podem ser inseridas naquilo que Barbalho e Castro expõem como diversificação institucional, dentro de um projeto de expansão do Ensino Superior. ${ }^{37}$ Essa diversificação se dá devido a interesses em missões distintas e diferentes, que buscam carreiras diferentes. ${ }^{38}$ Por isso, tais instituições são normalmente de iniciativa privada para atender a anseios específicos.

Ney alerta que, na construção de um Estado-Nação, há o pluripartidarismo que pode influir no processo educacional sim, tornando, por vezes, impossível a aplicação de uma educação neutra. "A educação neutra ocorre quando ela está desprovida de influências políticas e ideológicas, mas será que existe educação neutra?". 39

Assim, ao afirmar a necessidade de formar um cidadão consciente, criativo e de espírito crítico, entramos na complexidade da discussão acerca da educação neutra e da escola sem partido. É possível formar um cidadão consciente, crítico, sem aludir a alguma ideologia? Essa formação já não é também, de certa forma, uma posição ideológica?

\section{Ciências da Religião e Teologia na contemporaneidade}

Desde a separação estabelecida entre Igreja e Estado, Bacelar afirma que “[...] a Teologia não era considerada área de conhecimento pertinente ao Ensino Superior oficial $[\ldots]^{\prime \prime}, 40$ sendo oferecidos cursos de forma livre, não reconhecidos pelos órgãos estatais.

35 NEY, 2008, p. 141-142.

36 BARBALHO, Maria Goretti Cabral; CASTRO, Alda Maria Duarte Araújo. A nova arquitetura do ensino superior: a expansão e a diversificação no período pós-LDB (1995-2006). In: CASTRO, Alda Maria Duarte Araújo; FRANÇA, Magna. Política educacional: contextos e perspectivas da educação brasileira. Brasília: Liber Livro, 2012. p. 273.

37 Nessa questão da expansão do Ensino Superior, na área da Teologia, a partir do ano 2000 nota-se um crescimento de $67 \%$ com o surgimento de 14 novos programas de Mestrado e Doutorado. CAPES. Documento de Área - Teologia. Brasília, Ministério da Educação, Coordenação de Aperfeiçoamento de Pessoal de Nível Superior, $2016 . \quad$ Disponível em: <http://www.capes.gov.br/images/documentos/Documentos_de_area_2017/44_TEOL_docarea_2016.p df>. Acesso em: 20 jun. 2017. p. 4.

38 CASTRO; BARBALHO, 2012, p. 275.

39 NEY, 2008, p. 25.

40 BACELAR, Jeferson Antônio Fernandes. Breve Histórico da Educação Teológica Superior: da antiguidade aos dias atuais. Belém: Paka-Tatu, 2013. p. 145. 
Michele Nicoletti ${ }^{41}$ expõe que, a partir do século XIX, no campo da pesquisa, tanto para a Filosofia quanto da Ciência Política, a fé em Deus e a religião não são consideradas "objetos" relevantes, mas fenômenos regressivos. Defende que importante mesmo para a política é o sistema político e o sistema econômico, além dos aspectos institucionais da vida dos povos e dos Estados. Argumenta ainda que tanto a religião quanto a Teologia não são consideradas capazes de oferecer elementos de compreensão relevantes da realidade política.

Os primeiros passos foram trilhados a partir do Decreto-Lei n. 1051, de 1969:

Art $1^{\circ}$ Os portadores de diploma de cursos realizados, com a duração mínima de dois anos, em Seminários Maiores, Faculdade Teológicas ou instituições equivalentes de qualquer confissão religiosa, são autorizados a requerer e prestar exames, em Faculdade de Filosofia, Ciências e Letras, das disciplinas que, constituindo parte do currículo de curso de licenciatura, tenham sido estudadas para a obtenção dos referidos diplomas.

Art $2^{\circ}$ Em caso de aprovação nos exames preliminares, de que trata o artigo anterior, os interessados poderão matricular-se na faculdade, desde que haja vaga, independentemente de concurso vestibular, para concluir o curso, nas demais disciplinas do respectivo currículo. ${ }^{42}$

Mesmo atendendo às questões técnicas e normas da LDBEN, Bacelar menciona que a autorização (e reconhecimento) para oficialização dos cursos se deveu mais a pressões políticas. ${ }^{43}$ O Parecer n. 241, de 1999, estabeleceu que:

a) Os cursos de bacharelado em Teologia sejam de composição curricular livre, a critério de cada instituição, podendo obedecer a diferentes tradições religiosas. b) Ressalvada a autonomia das universidades e Centros Universitários para a criação de cursos, os processos de autorização e reconhecimento obedeçam a critérios que considerem exclusivamente os requisitos formais relativos ao número de horas-aula ministradas, à qualificação do corpo docente e às condições de infra-estrutura oferecidas. c) O ingresso seja feito através de processo seletivo próprio da instituição, sendo pré-condição necessária para admissão a conclusão do ensino médio ou equivalente. d) Os cursos de pós-graduação stricto ou lato sensu

41 NICOLETTI, Michele. Filosofia, Política e Teologia. In: PENZO, G.; GIBELLINI, R. (Org.). Deus na filosofia do século XX. São Paulo: Loyola, 1993. p. 595-615.

42 BRASIL. Decreto-Lei n. 1.051, de 21 de outubro de 1969. Provê sobre o aproveitamento em cursos de licenciatura, de estudos realizados em Seminários Maiores, Faculdades Teológicas ou instituições equivalentes de qualquer confissão religiosa. Disponível em: <http://www.planalto.gov.br/ccivil_03/decreto-lei/del1051.htm>. Acesso em: 25 jun. 2017.

43 BACELAR, 2013, p. 154. 
obedeçam às normas gerais para este nível de ensino, respeitada a liberdade curricular. ${ }^{44}$

A partir de então, o regramento vem sofrendo alterações com o intuito de melhorar e, com o Parecer n. 118, de 2009, passaram as instituições a precisar contemplar, "[...] em cumprimento aos eixos curriculares estabelecidos, disciplinas e conteúdos que garantam a cientificidade das teologias lecionadas". ${ }^{45}$

Propõe-se que os currículos dos cursos de graduação em Teologia, bacharelado, desenvolvam-se a partir dos seguintes eixos: 1. eixo filosófico - que contemple disciplinas que permitam avaliar as linhas de pensamento subjacentes às teologias, conhecer as suas bases epistemológicas e desenvolver o respeito à ética; 2. eixo metodológico - que garanta a apropriação de métodos e estratégias de produção do conhecimento científico na área das ciências humanas; 3. eixo histórico - que garanta a compreensão dos contextos culturais e históricos; 4. eixo sócio-político que contemple análises sociológicas, econômicas e políticas e seus efeitos nas relações institucionais e internacionais; 5. eixo linguístico - que possibilite a leitura e a interpretação dos textos que compõem o saber específico de cada teologia e o domínio de procedimentos da hermenêutica; 6. eixo interdisciplinar - que estabeleça diálogo com áreas de interface, como a psicologia, a antropologia, o direito, a biologia e outras áreas científicas. ${ }^{46}$

Nesse contexto das políticas educacionais brasileiras, a área da Teologia surge com a Portaria n. CAPES 174/2016,"47 para programas de Mestrado e Doutorado. De acordo com o Documento de Área - Teologia, a área Teologia se ocupa do campo de Estudos da Religião, mas não exclusivamente de Teologia em sentido estrito. Também o documento não pretende categorizar, conceituar ou reconfigurar o termo Teologia, nem mesmo desconsiderar as especificidades entre os estudos de Teologia e os de Ciências da Religião. Porém, determina que nesta área se "[...] desenvolve investigações que se orientam por abordagem de perfil multidisciplinar, interdisciplinar ou transdisciplinar [...]",48 abrangendo cursos de Mestrado Acadêmico e Doutorado, além do Mestrado Profissional em Ciências da Religião e em Teologia.

44 BRASIL. Parecer n. 241. Cursos Superiores de Teologia. 1999. Ministério da Educação. Conselho Nacional de Educação. Disponível em: <http://portal.mec.gov.br/cne/arquivos/pdf/1999/pces241_99.pdf>. Acesso em: 22 jun. 2017.

45 BACELAR, 2013, p. 166.

46 BRASIL. Parecer $n$. 118. Orientações para instrução dos processos referentes ao credenciamento de novas Instituições de Educação Superior e de credenciamento institucional que apresentem cursos de Teologia, bacharelado. 2009. Ministério da Educação. Conselho Nacional de Educação. Disponível em: <http://portal.mec.gov.br/dmdocuments/pces118_09.pdf>. Acesso em: 22 jun. 2017.

47 BRASIL. DOU. Portaria $n .174$, de 11 de outubro de 2016 . Disponível em: <http://capes.gov.br/images/stories/download/legislacao/20102016-portaria-capes-n-174-2016.pdf>. Acesso em: 20 jun. 2017.

48 CAPES, 2016, p. 2. 
Está subdividida em oito subáreas: Ciência da Religião Aplicada; Ciências da Linguagem Religiosa; Ciências Empíricas da Religião; Epistemologia das Ciências da Religião; História das Teologias e Religiões; Teologia Fundamental-Sistemática; Teologia Prática; e, Tradições e Escrituras Sagradas. Tal subdivisão exige “[...] uma pesquisa de perfil interdisciplinar entre as disciplinas que compõem a área e disciplinas de áreas afins" ${ }^{49}$

São disciplinas de áreas afins, com as quais preferencialmente se estabelece uma relação multi/inter/transdiciplinar na área Teologia: Antropologia, Arqueologia, Filosofia, Geografia, História, Linguística, Literatura, Psicologia, Sociologia, Teologia, entre outras da grande área de Ciências Humanas. 50

Em 2012, as coordenações de programas de pós-graduação, reunidos na Assembleia da Associação Nacional de Pós-Graduação e Pesquisa em Teologia e Ciências da Religião (ANPTECRE), deliberou que a área deveria ser nomeada como Ciências da Religião e Teologia.

Esta nomenclatura assegura o estudo sobre religiões e sobre teologia, considerando as epistemologias próprias, as teorias e métodos utilizados pelos dois grandes blocos de programas/cursos que compõem a área.

[...] o par formado por Ciências da Religião e Teologia, explicita de maneira adequada as oito subáreas da árvore do conhecimento já implementada no $\mathrm{CNPq}$ e em processo de recomendação para a nova árvore do conhecimento na CAPES.

A área assegura em seus procedimentos os princípios da laicidade do Estado e o rigor acadêmico na pesquisa sobre o objeto próprio que lhe compete investigar.

A área não se confunde com abordagens de caráter não científico ou pseudocientífico para o estudo das religiões e da teologia.

Tampouco reconhece, entre os seus Programas, abordagens de corte proselitista e fundamentalista, [...].51

Em Teologia, o pós-graduando tem como objetos de pesquisa, sempre numa perspectiva plural:

[...] a inteligência da fé, os conteúdos, as doutrinas, as tradições, os textos, as linguagens de tradições específicas, assim como as experiências que o ser humano desenvolve com o que reconhece e professa como sagrado, através do recurso a quaisquer outros saberes colaborativos, a partir da perspectiva interna e em diálogo com as demais ciências, com outras culturas, tradições

9 CAPES, 2016, p. 11.

50 CAPES, 2016, p. 13.

51 CAPES, 2016, p. 42. 
e religiões, considerada a diversidade de abordagens teórico-metodológicas de escolas e campos de estudos teológicos. ${ }^{52}$

A atuação deste pós-graduando em Teologia pressupõe sua preparação para atuar como pesquisador, docente e analista dos saberes dos objetos de pesquisa, além de atuar na formação de docentes para a educação básica ou nível superior, atuando como profissional especializado em questões relacionadas à religião de que é especialista no espaço público. 53

Para as Ciências da Religião, o Documento de Área estabelece que o pósgraduando pesquise:

[...] o fato religioso, a experiência religiosa, os fenômenos, as experiências, os conteúdos, as expressões, os textos, as tradições, as linguagens, as culturas religiosas e as tradições de sabedoria, considerados em perspectiva externa, em diálogo com outros saberes acadêmico-científicos, com ênfase em investigações de natureza qualitativa e quantitativa, podendo também ser de natureza teórica ou aplicada, a partir de abordagens teóricometodológicas próprias das escolas que constituem o campo de estudos da(s) religião(ões), suas subáreas e disciplinas auxiliares. ${ }^{54}$

As habilidades do egresso da pós-graduação em Ciências da Religião devem:

considerar a formação de habilidades para que o/a concluinte seja capaz de, enquanto pesquisador/a e/ou docente, analisar o fato religioso, os fenômenos religiosos e/ou as linguagens religiosas, desenvolvendo aproximações históricas e comparativas, sistemáticas e hermenêuticas das práticas e experiências religiosas humanas e das suas instituições sociais. ${ }^{55}$

Também a sua atuação é descrita:

como pesquisador/a, como docente e/ou como analista dos saberes e conhecimentos sobre/das práticas religiosas de uma ou de várias tradições, atuar na formação de docentes para a educação básica e/ou de nível superior, além de ser capaz de atuar como profissional especializado, consultor/a, assessor/a e/ou mediador/a em questões relacionadas à religião no espaço público. 56

Tanto em Teologia quanto em Ciências Teológicas, o Documento de Área enaltece a Teologia ao afirmar seu potencial para contribuir no enfrentamento dos desafios nacionais em:

\footnotetext{
CAPES, 2016, p. 9.

CAPES, 2016, p. 9.

CAPES, 2016, p. 9.

CAPES, 2016, p. 9.

CAPES, 2016, p. 10.
} 
[...] educação, ética e melhoria da qualidade de vida da população através da busca por compreensão aberta e plural das implicações que as cosmovisões religiosas, as espiritualidades e as teologias exercem junto à vida social, política e cultural do país. ${ }^{57}$

Além destas contribuições, o Documento atenta para a qualificação do debate acerca da sociedade plural, laica, do respeito à diversidade religiosa e à manifestação de crença ou de não crença, conforme, também, o ordenamento jurídico brasileiro. ${ }^{58}$

Também destaca a inserção no Ensino Fundamental e Médio, para a formação docente, destacando quanto foram decisivas a participação em debates sobre a Base Curricular para o Ensino Religioso e no desafio do debate agora pra as Diretrizes Curriculares para o Bacharelado e Licenciatura em Ciências da Religião e suas variações. ${ }^{59}$

\section{Considerações finais}

A educação pressupõe a participação de todos. Não é algo restrito à comunidade escolar. O debate para a construção de um sistema educacional de acordo com a realidade brasileira se faz necessário para que a educação possa ser pensada em suas diversas dimensões.

A educação, inserida dentro de um contexto de políticas públicas, não pode ser entregue às mãos de burocratas e ao poder público, somente. Ainda que seja função do poder público o regrar e institucionalizar a educação, a participação na elaboração de um sistema educacional pleno deve prever a participação de toda a sociedade. A educação é para esta sociedade e, como principal interessada, deve também participar da elaboração.

Há que se universalizar e democratizar o debate acerca da educação, tanto em termos de seu planejamento, como para possibilitar o acesso de todos. A educação é a mais importante política pública que um Estado deve abraçar. Através da educação a pobreza pode ser reduzida e, por consequência, a violência, a conscientização sobre consumo responsável, meio ambiente, enfim, pelo que cerca o cotidiano do ser humano.

Em linhas gerais, pode-se dizer que há uma preocupação para com uma política educacional brasileira atentando para as questões pertinentes ao desenvolvimento integral do ser humano. O fato de ser estar em permanente debate, por um lado, e a possibilidade da população em geral estar informada através das tecnologias da informação (denunciando e reivindicando) e, desta forma, poder participar da construção da educação brasileira, revelam a importância que a educação tem para o povo brasileiro.

59 CAPES, 2016, p. 13. 
Para fins de se refletir sobre as Ciências da Religião e Teologia, no entanto, fato é que, independente do plano de educação, qualquer política educacional deve dar tratamento primordial ao multiculturalismo, abrindo espaço para a diversidade.

O que se verifica a partir do exposto, é que no Brasil há sim uma preocupação com uma política educacional para as Ciências da Religião e Teologia. Há um esforço em se contemplar o multiculturalismo brasileiro, por um lado, e a cientificidade, por outro.

\section{Referências}

ABBAGNANO, Nicola. Dicionário de filosofia. São Paulo: Martins Fontes, 2007.

BACELAR, Jeferson Antônio Fernandes. Breve Histórico da Educação Teológica Superior: da antiguidade aos dias atuais. Belém: Paka-Tatu, 2013.

BARBALHO, Maria Goretti Cabral; CASTRO, Alda Maria Duarte Araújo. A nova arquitetura do ensino superior: a expansão e a diversificação no período pós-LDB (19952006). In: CASTRO, Alda Maria Duarte Araújo; FRANÇA, Magna. Política educacional: contextos e perspectivas da educação brasileira. Brasília: Liber Livro, 2012.

BRANDENBURG, Laude Erandi. A interação pedagógica no Ensino Religioso. São Leopoldo: Sinodal, 2004.

BRASIL. Decreto-Lei n. 1.051, de 21 de outubro de 1969. Provê sobre o aproveitamento em cursos de licenciatura, de estudos realizados em Seminários Maiores, Faculdades Teológicas ou instituições equivalentes de qualquer confissão religiosa. Disponível em: <http://www.planalto.gov.br/ccivil_03/decreto-lei/del1051.htm>. Acesso em: 25 jun. 2017.

DOU. Portaria n. 174, de 11 de outubro de 2016. Disponível em: <http:/ / capes.gov.br/images/stories/download/legislacao/20102016-portaria-capes-n174-2016.pdf>. Acesso em: 20 jun. 2017.

. Lei n. 9.394, de 20 de dezembro de 1996. Estabelece as diretrizes e bases da educação nacional. Disponível em: <http://www.planalto.gov.br/ccivil_03/leis/L9394.htm>. Acesso em: 15 jun. 2017.

- Parecer n. 118. Orientações para instrução dos processos referentes ao credenciamento de novas Instituições de Educação Superior e de credenciamento institucional que apresentem cursos de Teologia, bacharelado. 2009. Ministério da Educação. Conselho Nacional de Educação. Disponível em: <http:// portal.mec.gov.br/dmdocuments/pces118_09.pdf>. Acesso em: 22 jun. 2017.

Parecer n. 241. Cursos Superiores de Teologia. 1999. Ministério da Educação. Conselho Nacional de Educação. Disponível em: <http://portal.mec.gov.br/cne/arquivos/pdf/1999/pces241_99.pdf>. Acesso em: 22 jun. 2017. 
CAPES. Documento de Área - Teologia. Brasília, Ministério da Educação, Coordenação de Aperfeiçoamento de Pessoal de Nível Superior, 2016. Disponível em: <http://www.capes.gov.br/images/documentos/Documentos_de_area_2017/44_TEOL_ docarea_2016.pdf>. Acesso em: 20 jun. 2017.

CONSTITUIÇÃO DA REPÚBLICA FEDERATIVA DO BRASIL. 1988. Disponível em: <http://www.planalto.gov.br/ccivil_03/constituicao/constituicao.htm>. Acesso em: 15 jun. 2017.

FREIRE, Paulo. Pedagogia da Autonomia. 25. ed. São Paulo: Paz e Terra, 2002.

HÖFLING, Eloísa de Mattos. Estado e Políticas (Públicas) Sociais. Cadernos Cedes, ano XXI, n. 55, nov. 2001. p. 30-41. Disponível em: <http://www.scielo.br/pdf/ccedes/v21n55/5539.pdf>. Acesso em: 5 jun. 2017.

LIMA, Paulo Henrique; FARIA, Adriano A.. Proformar: tecnologia e informação para transformar a Amazônia. Disponível em: <https://www.academia.edu/5090929/PROFORMAR_Tecnologia_e_educação_para_tran sformar_a_Amazônia>. Acesso em: 10 jun. 2017.

MORIN, Edgar. Os sete saberes necessários à educação do futuro. 12. ed. São Paulo: Cortez; Brasília: UNESCO, 2007.

NEY, Antonio. Política Educacional: organização e estrutura da educação brasileira. Rio de Janeiro: WAK, 2008.

NICOLETTI, Michele. Filosofia, Política e Teologia. In: PENZO, G.; GIBELLINI, R. (Org.). Deus na filosofia do século XX. São Paulo: Loyola, 1993.

REIS, Daiane do Carmo. Liberdade Religiosa o Estado Laico: A Relação entre Religião, Estado, Política e Cultura na Contemporaneidade. Disponível em: <http://investidura.com.br/biblioteca-juridica/artigos/direito-constitucional/251509liberdade-religiosa-o-estado-laico-a-relacao-entre-religiao-estado-politica-e-cultura-nacontemporaneidade>. Acesso em: 04 jun. 2016.

SANTOS, Pablo Silva Machado Bispo dos. Guia Prático da Política Educacional no Brasil: ações, planos, programas e impactos. 2. ed. rev. ampl. São Paulo: Cengage Learning, 2014.

SHIROMA, Eneida Oto. Política Educacional. 4. ed. Rio de Janeiro: Lamparina, 2007.

VALCÁRCEL, Améli. Ética, um valor fundamental. In: MIRANDA, Danilo Santos de (Org.). Ética e cultura. São Paulo: Perspectiva/SESC, 2004. 